\title{
A prefixação no crioulo guineense: desfazendo e refazendo ações
}

\author{
Hildo Honório do Couto \\ Universidade de Brasília
}

\section{Abstract}

The aim of this article is to discuss the way the Portuguese Creole of Guinea-Bissau codifies the semantically opposite actions of undoing (DE-ACTION) and redoing (RE-ACTION) an act, not only morphologically, but also semantically and ecologically, i.e., in their interralations with the social ecosystem of which they are part. In the lexifier language (Portuguese), they are codified prefixally, namely, by means of des- 'un-, de-' and re- 're-', respectively. Using the methodology of corpus linguistics, I show that the creole codifies only DE-ACTION morphologically, via the prefix dis-. As to RE-ACTION, lt is expressed only syntactically, by means of the equivalent of "again", exactly as in children's speech. The findings are compared to what happens in other lexifier creoles and in Portuguese. Some suggestions are given for why creole has only the prefix $d i s$-, but not its opposite. Finally, I suggest that the behavior of dis- in this language calls for an independent morphological component of the grammar roughly like what can be seen in lexical phonology and morphology. 


\section{INTRODUÇÃO}

$\mathrm{N}$

ormalmente se diz que as línguas crioulas não têm morfologia ou, quando a têm, trata-se de pouca morfologia 1998). Essa tese está longe de ser consensual, como se pode ver em DeGRAFF (2000). Além do mais, afirma-se que, pelo menos nas línguas ocidentais, o processo morfológico da sufixação predomina frente ao da prefixação. Há mesmo estudiosos que afirmam que a prefixação não seria um processo derivacional, mas composicional. O crioulo português da Guiné-Bissau apresenta alguns processos morfológicos sufixais e flexionais (cf. COUTO, 1994; KIHM, 1994). No domínio da prefixação, de modo indiscutível o guineense parece ter apenas o prefixo dis-. É dessa questão que vou tratar aqui.

Várias línguas do mundo morfologizam o ato de se desfazer (doravante, DES-AÇÃO) e o de se repetir ou refazer (doravante, REAÇÃO) uma ação, ou seja, codificam-no prefixalmente. Depois de discutir a ecologia do desfazer e do refazer ações, tento mostrar que nas línguas românicas os dois atos são codificados por prefixos, que por sinal são dois dos mais produtivos, fato que se verifica em outras línguas, como as germânicas, as eslavas e outras. Com isso, chegamos ao objetivo central deste artigo, que é mostrar como o guineense codifica essas ações. Os exemplos foram tirados sobretudo de narrativas orais que se encontram publicadas. Como se sabe, a ação é o componente central desse tipo de manifestação verbal. Logo, é de se esperar que muitas ações sejam desfeitas e muitas outras refeitas ou retomadas. Veremos que apenas o ato de desfazer ações se codifica prefixalmente no guineense. O de refazer ações é expresso sintaticamente.

Comecemos pela ecologia desses atos em si mesmos. Algumas conjeturas serão apresentadas sobre o porquê de DES-AÇÃO estar 
morfologizada e de RE-AÇÃO não estar. O mais importante, no entanto, é que o comportamento do único prefixo produtivo guineense parece justificar a necessidade de um modelo morfológico não-linear, com pelo menos quatro camadas (tiers).

\section{DESFAZENDO E REFAZENDO AÇÕES}

A intervenção do ser humano no mundo consiste basicamente de ações sobre aspectos do meio ambiente. O mais comum é essas ações serem praticadas uma única vez. Porém, muitas delas produzem efeitos indesejáveis/desagradáveis, motivo pelo qual freqüentemente se deseja reverter seu resultado. Outras, sobretudo as que têm efeitos desejáveis/agradáveis, freqüentemente são repetidas (refeitas). É por isso que muitas línguas têm recursos morfológicos para codificá-las. É o caso das línguas românicas, das germânicas, das eslavas e outras. Tanto na DES-AÇÃO quanto na REAÇÃO, trata-se de retomar determinada ação. No primeiro caso, para se desfazer de seu resultado; no segundo, para se obtê-lo mais uma vez.

No domínio da informática e da tecnologia em geral, isso pode ser constatado a todo momento. Por exemplo, quando instalamos determinado programa em nosso computador, pode ser que ele não seja exatamente o que queríamos. Nesse caso, podemos desinstalálo. No entanto, podemos nos arrepender do último ato, e reinstalálo. Há várias outras tríades como essa: ligar x desligar x religar, configurar $\mathrm{x}$ desconfigurar $\mathrm{x}$ reconfigurar, etc. Para alguns atos, não há todos os termos, como inicializar $\mathrm{x}$ - x reinicializar (em vez de * desinicializar, usa-se fechar, desligar, etc.); copiar x apagar/deletar $\mathrm{x}$ copiar de novo. O mesmo vale para abrir, baixar e outros.

Até o presente momento da investigação, parece que há dois tipos básicos de DES-AÇÃO. O primeiro consiste em refazer o que havia sido desfeito (e que tinha sido feito antes de ser desfeito), como indicam os exemplos da informática recém-vistos. O segundo consiste em retomar algo não necessariamente que tenha sido desfeito, mas sobre que se deseja fazer uma revisão. Por exemplo, 
uma área urbana pode ser (ou está) zoneada, dividida em regiões. A certa algura, a administração chega à conclusão de que seria melhor rezoneá-la, não porque ela tenha sido *deszoneada, mas porque se constatou que seria bom zoneá-la diferentemente. Outro exemplo: os filhos que herdam uma grande fazenda do pai a dividem. Os filhos deles, ao herdarem-na, redividem-na, sem que ela tenha sido *desdividida, mas sim porque uma nova divisão se fez necessária. Nos dois casos, apenas se estruturou diferentemente algo já estruturado. Não se tratava de reestruturar algo que havia sido desestruturado.

$\mathrm{Na}$ interação da criança com os adultos, no processo de aquisição da L1, muitas ações são desfeitas/retomadas. Não tenho muita informação sobre o ato de refazê-las. Sobre o de desfazê-las, no entanto, existe pelo menos todo o capítulo 12 de CLARK (1993), intitulado "Words for undoing actions" (p. 219-238). Ela mostra que o inglês tem diversos recursos para expressar DES-AÇÃO, tais como fold/unfold, switch on/off e lose/find, mas que apenas o primeiro exemplo faz parte de uma estratégia produtiva (prefixação). Segundo essa autora, por volta de 4 anos de idade as crianças a assimilam, inclusive superproduzindo formas com o prefixo un-, como em unclimb, unmix e unput por climb down, separate e take X out, respectivamente. A autora afirma que o alemão não dispõe de um prefixo equivalente, recorrendo no caso a partículas como auf, aus e $a b$. Assim, as crianças produzem formas como abschnuren 'desamarrar o sapato' de Schnur 'cadarço', sendo que a forma do adulto é abbinden. Entretanto, devo observar que no alemão padrão existe o prefixo ent-, que ocorre em formas como entfesseln 'desatar' de fesseln 'atar'. Ainda de acordo com Clark, as crianças holandesas procedem como as inglesas, ou seja, iniciam por partículas separáveis (af, uit), mas logo se apropriam do prefixo negativo ont-, que ocorre em palavras como ontschepen 'desembarcar' de schepen 'embarcar'. A autora mostra que processos semelhantes se encontram nas línguas eslavas e no húngaro, além das línguas românicas.

Embora CLARK (1993) não trate da RE-AÇÃO, o processo é muito importante na linguagem das crianças e em nossa ação sobre 
o mundo. Para indicá-la, geralmente a criança faz uso da expressão de novo, mas na linguagem dos adultos o ato está freqüentemente codificado pelo prefixo re- que, em algumas variedades da língua, ocorre mais do que des-, como veremos logo abaixo. Em outras línguas o primeiro deles é provavelmente tão freqüente quanto no português. Em inglês temos o mesmo re-de origem latina. No alemão faz-se uso do advérbio wieder 'de novo', que funciona como partícula separável, como se pode ver em wiederaufbauen 'reconstruir', de aufbauen 'construir'.

Na variedade padrão do português brasileiro atual, as duas ações em questão são produtivamente codificadas pelos prefixos românicos des-e re-, respectivamente. Em uma sondagem prévia em todos os textos da edição de 17/11/2000 do jornal Correio Braziliense, constatei que os dois prefixos são altamente recorrentes, e quase em condição de igualdade, com uma ligeira vantagem para o segundo deles. Assim, o prefixo re- ocorreu 106 vezes, em 48 palavras diferentes, enquanto que des- ocorreu 91 vezes, em 45 palavras diferentes. Até mesmo nos casos polêmicos (ex.: ressarcir, revogar, desabafo, descarado), essa proporção se manteve, ou seja, reocorreu 55 vezes em 25 palavras diferentes e des- ocorreu 29 vezes em 16 palavras diferentes. Para corroborar essa tendência, constatei que na primeira edição do Novo dicionário Aurélio, há 40 páginas de entradas iniciadas por re-e 31 por des-. Embora nem todas elas contenham esses prefixos (ver reza e destino), o interessante é que a tendência geral se manteve. Em SANDMANN (1989), no entanto, houve uma inversão dessas estatísticas: des- ocorreu em 49 palavras e re-em 35. Será que isso teria a ver com o momento de transição da ditadura para a democracia?

PINTO (1994) demonstrou que, a despeito da grande profusão de prefixos (vernáculos, latinos e gregos) do português padrão, nas variedades rurais do PB há praticamente apenas três relativamente produtivos. São eles justamente re-, des-e in-. No último se inclui tanto a variante que indica negação (injustiça) quanto a que indica movimento para dentro (injeção). A autora demonstrou outrossim 
que nos crioulos portugueses a quantidade de prefixos é diretamente proporcional à sua distância tipológica relativamente ao português. Assim, o caboverdiano tem os equivalentes a des-, re-, in- e con-. O guineense, em sua variedade basiletal, apresenta apenas o prefixo des-. Um fato interessante constatado pela autora é que re-e des-são os prefixos mais freqüentes do português brasileiro.

Diante das constatações que veremos mais abaixo, impõemse as perguntas: 1) por que justamente re-e des-são os prefixos mais comuns na língua portuguesa? 2) por que dos dois justamente re-é mais comum no português padrão? 3) por que nas variedades rurais do português brasileiro, na linguagem infantil e no crioulo guineense é desque predomina? Embora meu objetivo não seja responder a elas, algumas sugestões de resposta podem ser respigadas aqui e ali no texto.

\section{PREFIXAÇÃO}

Como tanto a RE-AÇÃO quanto a DES-AÇÃO são codificadas prefixalmente em muitas línguas do mundo, gostaria de discutir brevemente a própria prefixação. Nas línguas da Europa, sobretudo nas do tronco indo-europeu, o processo derivacional mais comum é o da sufixação. Entretanto, em línguas de outras famílias pode predominar a prefixação. É o caso da língua khmer e das línguas do grupo athabaska (navaho, apache, hupa e chipewya) da América do Norte e, até certo ponto, o chinook (SAPIR, 1971, p. 75-76). Se considerarmos os pronomes clíticos de muitos crioulos (inclusive os crioulos portugueses) e de línguas africanas, bem como os conhecidos morfemas de classe, o conjunto de línguas que fazem amplo uso de prefixos aumenta consideravelmente.

Geralmente se diz que nas línguas indo-européias a prefixação não muda a categoria da palavra, embora em outras línguas isso possa ocorrer, como em tagalog. Nas línguas românicas, ela tende a acrescentar ao radical a idéia de movimento, geralmente afastamento/ aproximação, posição, negação e intensificação. Segundo POTTIER 
(1964), isso se deve ao fato de os prefixos praticamente não se distinguirem das preposições, palavras que por natureza indicam essas relações. Assim, de seria o mesmo em decedere de vita e de sella exsiluit em latim (p. 276-277). Do mesmo modo, em francês o de inicial de decouler é o mesmo de couler de la montagne, o que ficaria mais explícito se mudássemos a ordem das palavras para de [la montagne] couler (p. 198). A preposição de valor oposto $a d$ tem aproximadamente o mesmo significado nas suas duas ocorrências de adesse ad urbem.

É interessante notar que o prefixo mais freqüente do português (re-) não é preposição, tendo vindo como tal do latim, como se vê em refrigesco (intensivo), retego e reprobus (negativo). Mas, "re indica essencialmente a repetição. Em sua aplicação espacial, a repetição se traduz pela volta ao ponto de partida, a volta atrás; vejase, por exemplo, o latim reducere ou recurrere. Em sua aplicação temporal, como o tempo não é reversível, significa iteração, como em refazer. Em sua aplicação nocional existem as duas possibilidades citadas. O movimento espacial, a volta atrás, dá o sentido negativo, o de recludo 'abrir'. A iteração dá o sentido intensivo, de recludo 'fechar por completo' (POTTIER, 1962, p. 20, 22).

Do ponto de vista da combinabilidade, POTTIER (1962, p. 100) afirma que "os prefixos podem combinar-se entre si: re-dé-couper. Alguns não podem ser segundo prefixo (re-)". Em (1) temos alguns exemplos dos que combinam, tirados do Aurélio. Aí se inclui até o re-como segundo prefixo (iv), contradizendo Pottier.

(1) (i) in.des.mobilizável, in.des.atável, in.des.viável;

(ii) ir.re.ajustável, ir.re.elegível, ir.re.iterável;

(iii) des.in.compatibilizar; (iii') des.in.feliz, des.in.quieto;

(iv) des.re.vestir-se, des.re.folhar.

Aparentemente, quando se acrescenta mais um prefixo a uma palavra já prefixada, o prefixo já existente tende a perder sua autonomia, ou seja, a palavra tende a ser vista como um todo indecomponível. Isso parece se aplicar sobretudo aos exemplos de (1iii') e de (1iv). 
Nos outros, parece que cada prefixo ainda mantém uma identidade claramente detectável. Os exemplos de (1iii') demonstram que quando des combina com uma base que já contém um prefixo de valor negativo (in-) passa a ter o valor de intensivo. Seria uma reduplicação, pelo menos semântica, da negatividade.

\section{PREFIXAÇÃO NO GUINEENSE}

Segundo ROUGÉ (1988, p. 18) e COUTO (1994, p. 87), o guineense só teria o prefixo dis-. Entretanto, SCANTAMBURLO (1999, p. 142) afirma que existem cinco, ou seja, anti-, ba-, dis-, gan- e $k a-$, sendo que dis- poderia formar substantivos ou verbos. Os exemplos fornecidos por ele são os que se vêem em (2).

(2) (i) antikolonialista, (ii) Ba-Pedru 'os familiares de Pedro ou as pessoas que estão com Pedro'; (iii) animadur-disanimadur, dinguidu-disdinguidu 'saído da solidão', konfiadu-diskonfiadu 'suspeito', kubri-diskubri ‘descobrir'; (iv) Gan-Mamadu 'aldeia Mamadu', Gan-Biafada 'região do povo beafada'; (v) balikabalidu 'inapto'/kabalindadi 'incapacidade', pudi-kapudi 'estar doente'

No meu corpus, ocorreram todas as formas mencionadas por Scantamburlo, exceto anti-. Ocorreram também outras formas que têm alguma aparência de prefixo, ou seja, ru-, di-, mal-. Em (3) vêem-se as palavras em que ocorreram.

(3) (i) rukuji-kuji 'recolher-colher'; (ii) ditardi-tardi, dipresa-presa, dinoti-noti, dikosta-kosta, dimenoti-menoti, dimas-más, diriba-riba, dibas-bás, direpenti-repenti; (iii) malmandadu-mandadu

Com isso o número de prefixos guineenses subiria para sete, ou oito, se admitirmos anti-. Entretanto, muitos deles são discutíveis. Comecemos por mal-. Ele ocorreu uma única vez, e não nas narrativas, mas em um provérbio, que reproduzo em (4). 
(4) Deus i sta lundju di nos, ma i ka malmandadu 'Deus está longe de nós, mas ele é confiável'

Quanto a $d i$-, poder-se-ia dizer que é uma preposição que estaria sendo usada exatamente como de português em de tarde, de noite, etc. Embora POTTIER $(1962,1968)$ tenha demonstrado que nas línguas românicas as preposições são fonte constante de prefixos e que praticamente não há diferença semântica considerável entre ambos, o caso guineense não é muito claro. A posição mais prudente parece ser a de excluir essa forma do rol dos prefixos.

No que tange a ru-, o exemplo (3i) parece nos autorizar a considerá-lo um caso de prefixação, com o que teríamos pelo menos uma ocorrência de RE-AÇÃO codificada prefixalmente. Poder-se-ia inclusive afirmar que ele teria os alomorfes $r a$-e $r i$-, como se vê em palavras como rapati 'repartir' - por oposição a pati 'dar' -, ripindi 'arrepender-se' e ripiti 'repetir'. Uma possível segmentação ri-piti se justificaria, em princípio, no modelo morfológico apresentado na seção 7. Fora do meu corpus, encontrei uma única ocorrência da palavra re.kumenda que, no entanto, é empréstimo do português. De qualquer forma, apenas um exemplo inequívoco não parece suficiente para justificar a existência de mais um prefixo derivacional na língua. Afinal, que prefixo é esse que permite derivar uma única palavra?

As três formas restantes ( $b a$-, gan- e $k a$-) têm mais aparência de prefixos, mas, será que realmente o seriam? Além dos exemplos dados acima, poderíamos acrescentar os de (5).

(5) (i) Gan-Fodeba 'a terra de Fodeba', Gan-fula 'a terra dos fulas'; (ii) ba-quissas 'coisas', ba-Maneles 'os Manoéis', Ba-Finas 'as Finas, nome próprio', Ba-Tat 'os Tates, nome próprio', ba-jobê 'os curiosos, os basbaques', ba-Safinté 'os Safins' (Cf. BARROS 1897-1899, p. 178, 272)

De acordo com KIHM (1994, p. 129), ba-provém do prefixo de classe 2 que denota pluralidade para seres humanos, muito comum nas línguas atlânticas, tais como o manjaco, o balanta e o diola. Como 
se pode ver em BARROS (1897-1899), ele parece ter sido relativamente produtivo, mas hoje seu uso parece estar lexicalizado. Quanto a gan-, equivale aproximadamente ao con 'chão, terra' do crioulo, como em con di pepel 'terra dos pepéis'. Seria como o -ia que ocorre em palavras como Ibéria 'terra dos iberos', Rússia 'terrra dos russos' e assim por diante. Para Kihm gan-só ocorreria em alguns itens já lexicalizados. Isso siginfica que esses prefixos estariam, quando muito, no nível morfológico 4 do modelo apresentado na seção 6 .

A forma $k a$ - 'não' ocorre em tão poucos exemplos que podemos perguntar se efetivamente poderia ser considerada um prefixo ou uma forma livre que entra em composições esporádicas. Eis os que encontrei: kasabi 'coisa desagradável', kabali 'que ou o que não presta', de que deriva kabalindadi 'qualidade do que não presta'. Portanto, parece mais um exemplo de composição.

Diante do exposto nesta seção, o único prefixo indiscutivelmente produtivo do guineense é dis-, de que já vimos quatro exemplos em (2iii). Uma vez que ele normalmente indica DES-AÇÃO, voltarei a ele na seção seguinte, estudando-o detalhadamente, em comparação com o recurso para RE-AÇÃO.

\section{DESFAZER E REFAZER AÇÕES NO GUINEENSE}

Investiguei 70 fábulas tiradas de PEREIRA (1988), PEREIRA (1989), MONTENEGRO/MORAIS (1979), MONTENEGRO/MORAIS (1995) e MONTENEGRO/MORAIS (1994-1996), bem como 466 provérbios (ANDREOLETTI [s.d.]). Tentei usar a metodologia da ligüística de corpus (cf. BIBER, CONRAD \& REPPEN, 1998) com o software Contexto, desenvolvido por Jehferson Wollherz de Mello. Num universo de 70.426 palavras do corpus, encontrei 20 palavras que contêm o prefixo dis-, enumeradas no Quadro 1, seguidas do número de ocorrência, da porcentagem, do significado e da base, quando ela tem autonomia. 


\section{Quadro 1}

\begin{tabular}{|c|c|c|c|c|}
\hline Palavra & N. de ocor. & Porcentagem & Significado & Base \\
\hline dis.kisi & 18 & $13,43 \%$ & esquecer & $?$ \\
\hline dis.kansa & 15 & $11,19 \%$ & descansar & kansa \\
\hline dis.kuda & 15 & $11,19 \%$ & descuidar-se & kuda \\
\hline dis.pidi & 14 & $10,44 \%$ & despedir-se & $?$ \\
\hline dis.manca & 13 & $9,70 \%$ & desmanchar & $?$ \\
\hline dis.mara & 11 & $8,20 \%$ & desamarrar & mara \\
\hline dis.kunfia & 8 & $5,97 \%$ & desconfiar & kunfia \\
\hline dis.pi & 7 & $5,22 \%$ & despir & $?$ \\
\hline dis.tindi & 6 & $4,47 \%$ & estender & $?$ \\
\hline dis.kulpa & 4 & $2,98 \%$ & desculpar & kulpa \\
\hline dis.pindra & 4 & $2,98 \%$ & despendurar & pindra \\
\hline dis.maia & 4 & $2,98 \%$ & desmaiar & $?$ \\
\hline dis.aparsi & 3 & $2,23 \%$ & desaparecer & parsi \\
\hline dis.kubri & 2 & $1,49 \%$ & descobrir & kubri \\
\hline dis.tapa & 2 & $1,49 \%$ & destapar & tapa \\
\hline dis.gustu & 2 & $1,49 \%$ & desgosto & gustu (?) \\
\hline dis.afiu & 2 & $1,49 \%$ & desafio & $?$ \\
\hline dis.dangu & 2 & $1,49 \%$ & desdém & $?$ \\
\hline dis.almadu & 1 & $0,74 \%$ & desalmado & alma \\
\hline dis.kuson & 1 & $0,74 \%$ & discussão & $?$ \\
\hline Total & 134 & $99,91 \%$ & & \\
\hline
\end{tabular}

Há algumas ocorrências que não parecem ser exemplos de prefixação. Por isso, os 20 exemplos são reorganizados no Quadro $2 \mathrm{a}$ fim de que as diferenças entre elas fiquem realçadas. Estas quatro classes correspondem aos quatro níveis do componente morfológico da gramática discutidos na seção 7 . 
Quadro 2

\begin{tabular}{clll}
\hline (i) & \multicolumn{1}{c}{ (ii) } & \multicolumn{1}{c}{ (iii) } & (iv) \\
\hline dis.kansa & dis.tindi & dis.almadu & dis.kisi \\
dis.kuda & dis.kulpa & dis.kuson & dis.pidi \\
dis.mara & dis.gustu & & dis.manca \\
dis.kunfia & & & dis.pi \\
dis.pindra & & & dis.maia \\
dis.aparsi & & & dis.afiu \\
dis.kubri & & dis.dangu \\
dis.tapa & & & \\
\hline
\end{tabular}

Os exemplos (i) do Quadro 2 parecem ser os únicos que não apresentam nenhum problema de monta. A forma com o prefixo disgeralmente indica exatamente a ausência ou o desfazimento da ação indicada pelo radical verbal. Os exemplos seguintes são todos problemáticos, de uma forma ou de outra. Os de (ii) nem tanto, uma vez que a base existe independentemente ( $k$ ulpa, gustu) ou o dispode ser comutado por outro presumível prefixo (Ntindi 'entender'). Os de (iii) são empréstimos do português, portanto, são analisáveis como o são nessa língua. Os mais problemáticos são os de (iv): a base não existe independentemente nem admite a troca de dis-por outro formativo. No item 7 apresento uma proposta de interpretação para eles.

Foram ignoradas as flexões e derivações. Assim, diskunfia ocorreu também como diskunfiadu, dismara apareceu sob a forma dismaran 'desamarre-me' e assim por diante. A base de disaparsi não é propriamente *aparsi mas parsi. Quanto a diskubri, apareceu também sob a forma duskubri. Disgustu tem a forma alternativa disgostu. A alternância fonética entre [u] e [o], por um lado, e [i] e [u], por outro, não é incomum, embora esteja longe de ser sistemática. Por fim, dispindra ocorreu algumas vezes como disprinda, num processo metatético que revelaria insegurança dos falantes quanto à forma da palavra. Entretanto, nenhuma dessas questões interessa diretamente à morfologia. 
Há outros dados que requerem comentários mais detalhados. Começando por disgostu, nota-se que não é necessariamente o contrário ou o desfazimento de gostu, exatamente como ocorre em português. De qualquer forma, o significado da base não se altera por completo, o prefixo dis- mantém sua identidade fonológica e semântica e, o que é muito importante, o significado total da palavra contém a mesma idéia de DES-AÇÃO que as de (i), tipicamente indicada pelo prefixo dis-

Alguns dos exemplos sequer têm a contraparte sem dis-. Quando existe um morfema cuja conformação fonológica é idêntica ou semelhante ao que seria essa contraparte, ele não tem nada a ver com o complexo "dis + base". Isso nos levaria a questionar se efetivamente contêm o prefixo ou se se trata de formas indecomponíveis. Dismanca, por exemplo, vem do português desmanchar que, por seu turno, já veio pronta do francês, onde se decompõe em dé- e manche, ou des-e mancher no francês antigo, com a mesma semântica e estrutura morfológica dos exemplos (i) do Quadro 1 (ver POTTIER, 1962, 1968). A propósito de diskisi afirma KIHM (1994, p. 271) que tem origem no português esquecer. "A primeira sílaba foi aparentemente 'remotivada', o que confirma a presença do prefixo na forma do kriol". Em suma, se levarmos o significado de dis-até suas últimas conseqüências, as palavras de (ii), (iii) e (iv) parecem indicar, todas, DES-AÇÃO. Além disso, parece haver razões morfológicas também para incluir esse grupo de palavras no rol das prefixadas. Uma vez identificado determinado formativo, pode-se prever sua ocorrência mesmo que o elemento com o qual combina não exista como forma livre nem como forma presa em outros contextos.

O caso mais complicado parece ser o de disdangu. De acordo com ROUGÉ (1988, p. 50), existem "diversas explicações possíveis: [ele foi] construído sobre o mandinga danku, responder a uma saudação (dis+danku). Pode-se aproximá-lo do bambará danga, 'maldizer' (no crioulo caboverdiano dangu tem o mesmo sentido). Pode-se ver também em sua origem o português desdenhar. Provavelmente trata-se da confluência de tudo isso". Para BARROS 
(1897/1899, p. 288), disdangué "termo composto do verbo mandinga dam-cum, responder, e da preposição portuguesa des". Quer esses argumentos sejam válidos quer não, o fato é que disdangu contém dis-no início e semanticamente é parecido com os exemplos de (i), ou seja, contém a idéia de DES-AÇÃO. Portanto, o dis-que aí ocorre é o mesmo formativo da gramática morfológica que ocorre nos exemplos de (i) e (ii).

No que concerne à RE-AÇÃO, o guineense não a codifica prefixalmente, ou seja, morfologicamente, mas apenas sintaticamente, a despeito do hapax legomenon de (3i). No corpus mencionado acima, ela ocorreu em grande quantidade sob essa forma, embora às vezes seja difícil distingui-la de continuidade de ação. Parece haver uma certa afinidade entre ambas, embora eu não tenha condição de resolver a questão no momento. Tendo essa ressalva em mente, o corpus mostrou que o guineense faz uso de três estratégias para expressar RE-AÇÃO. A primeira delas está exemplificada em (6), ou seja, a que se expressa pelo esquema "torna V".

(6) (i) mininus torna ientra 'os meninos entraram de novo'

(ii) lubu torna pui pe na tarbaju 'o lobo se pôs a correr de novo' (lit. 'tornou a pôr pé no brabalho')

(iii) i torna sinta 'ele sentou-se de novo'

(iv) i torna bai 'ele foi de novo/ retornou'

A segunda estratégia para indicar repetição é a que se manifesta pelo esquema "V mas", como se vê nos exemplos de (7).

(7) (i) N ka fia e bo kunbersa. Son si bu kunsa mas 'eu não acredito nessa sua conversa, a não ser que você comece de novo/recomece'

(ii) i riba li mas 'ele chegou aqui de novo / reapareceu aqui'

(iii) i riba mas dentru 'ele veio aqui dentro de novo' 
A terceira estratégia, bem menos freqüente, para indicar REAÇÃO combina as duas anteriores, redundando no esquema "torna V mas". Em (8) temos dois exemplos.

(8) (i) minjer torna kanta mas 'a mulher voltou a cantar / cantou de novo'

(ii) i ta torna ria mas 'ele voltou a descer / desceu de novo'

Há onze ocorrências de difícil classificação. Entrariam em "torna V", "V mas" ou "torna $\mathrm{V}$ mas"? Na figura abaixo eles entram como Outros. Vejam-se os três exemplos de (9).

(9) (i) e pidi mas dus saku 'eles pediram mais dois sacos / eles pediram de novo dois sacos' (?)

(ii) $\mathrm{N}$ ta torna mas pior kuma $\mathrm{N}$ sta ba 'eu vou ficar pior do que estava' (?)

(iii) i ka mas i torna toma 'ele não vai conseguir tomá-lo de novo/retomá-lo' (?)

Na verdade, há outras maneiras de indicar RE-AÇÃO. Entre elas temos o morfema bin ( $\tilde{n}$ u fereru bin san 'o senhor ferreiro voltou [veio] a ficar são / ficou são de novo'), a estrutura "V ku V" (bu sibi $k u$ sibi 'você sobe e desce / você fica subindo e descendo') e a reduplicação (no pika-pika 'nós cortamos e cortamos de novo'). No entanto, nenhum deles parece ser tão incisivo como os exemplificados em (7)-(9), que constituem a estratégia preferida para essa finalidade. No quadro abaixo, pode-se ver as estatíticas de ocorrência dessas expressões no corpus. 


\section{Quadro 3}

\begin{tabular}{lcc}
\hline Esquema & número de ocor. & porcentagem \\
\hline torna $\mathrm{V}$ & 58 & $43,28 \%$ \\
$\mathrm{~V}$ mas & 51 & $38,05 \%$ \\
torna V mas & 14 & $10,44 \%$ \\
outros & 11 & $8,20 \%$ \\
\hline Totais & 134 & $99,97 \%$ \\
\hline
\end{tabular}

As ocorrências de DES-AÇÃO expressas prefixalmente (134) são numericamente iguais às de RE-AÇÃO. Como se pode ver nos Quadros 1 e 2, o corpus contém 20 palavras com o prefixo dis-, num total de 134 ocorrências. A questão que se põe é a seguinte: por que DES-AÇÃO está morfologizada, e não RE-AÇÃO, que é tão freqüente quanto ela?

A possível causa para a ausência de re-e da presença de disnas situações vistas acima parece estar no ambiente social em que a língua é usada. Não se trata de uma questão meramente lingüística.

\section{DES-AÇÃO E RE-AÇÃO EM OUTROS CRIOULOS}

Em outros crioulos de base européia, parece que as tendências acima constatadas se mantêm. Por exemplo, tanto em DeGRAFF (2000) quanto em BROUSSEAU, FILIPOVICH \& LEFEBVRE (1989) se nota que só DES-AÇÃO se morfologiza no haitiano, como se pode ver nos exemplos de (10).

(10) (i) de.mare 'desatar' / mare 'atar'

(ii) de.respekte 'desrespeitar' / respekte 'respeitar'

(iii) de.grese 'emagrecer' / grese 'engordar'

Há até mesmo outros prefixos, tais como ti-(pequeno) e en-, que ocorrem em palavras como ti.pyebwa 'arbusto' (bwa 'árvore') e en.koutab 'audacioso' (koute 'ouvir'). Porém, o recurso para RE-AÇÃO está ausente. É bem verdade que no reunionês ambos 
ocorrem, como nos exemplos de (11), tirados de CHAUDENSON (1974, p. 1041, 1044).

(11) (i) de.brãse 'desgalha' / brãs 'galho'; de.zike 'tirar a nervura' (zik) de uma palmeira.

(ii) re.fósé 'furar uma fossa de novo' / fósé 'furar uma fossa'

É interessante notar que o autor apresenta pelo menos oito exemplos de formações com $d e$-, mas apenas quatro com re-que, além disso, pode aparecer sob a forma dos alomorfes $a:^{r}-$ e $r$ - Isso mostra que, mesmo quando há recurso morfológico prefixal para a RE-AÇÃO, a DES-AÇÃO predomina nessa língua. A própria variação fonológica sugeriria uma maior debilidade da RE-AÇÃO. Deve-se notar que o reunionês é tão distante dos crioulos prototípicos que HOLM (1991) o considera um semi-crioulo, ou seja, muito mais próximo do francês do que outros crioulos franceses.

Aparentemente, nenhum crioulo inglês codifica esses dois atos morfologicamente, a despeito de na língua lexificadora tanto dequanto re-serem relativamente produtivos, como se pode ver em LIEBER (1992, p. 1-9).

\section{MORFOLOGIA LEXICAL}

Os exemplos do Quadro 1 parecem requerer um modelo morfológico semelhante ao que se vê na fonologia lexical, ou seja, a morfologia lexical (KIPARSKY, 1982; PAULISSEN \& ZONNEVELD, 1988), com quatro níveis. Se esta proposta for válida, cada grupo de exemplo do Quadro 2 entraria em um dos níveis, estratos ou camadas (tiers) vistos a seguir. 


\section{Níveis da morfologia lexical}

Nível 1: diskansa; diskubri; diskuda; diskunfia; dismara; dispindra; distapa; disaparsi (i)

Nível 2: disgustu, diskulpa, distindi (ii)

Nível 3: disalmadu, diskuson (iii)

Nível 4: dismanca; disafiu; dispidi; diskisi; dismaia; disdangu, dispi (iv)

No nível 1 entrariam as palavras cuja base mantém o signficado que tem alhures e/ou quando ocorre isolada. Por exemplo, kansa tem aproximadamente o mesmo significado em diskansa. O significado adicional é indicado pelo prefixo. No caso, kansa quer dizer 'cansar', ao passo que diskansa significa 'desfazer o cansaço'. Enfim, no nível 1 entram as construções produtivas e semanticamente transparentes.

O nível 2 é aquele em que entram complexos vocabulares cuja base mantém o signficado de quando ocorre isolada apenas parcialmente. É o caso de disgustu. A base desse complexo compartilha apenas alguns traços semânticos com gustu. Pelo menos aparentemente, não se formam palavras desse nível a qualquer momento, além de a palavra ter ocorrido apenas duas vezes, o que significa que não se trata de construções totalmente transparentes, embora não sejam inteiramente opacas como as de nível 4.

No nível 3 entram as construções que, mesmo obedecendo os princípios válidos para as de nível 1 e, sobretudo as de nível 2, não são produtivas na língua. Em geral provêm da língua lexificadora português. De qualquer modo, qualquer falante de crioulo que conheça o prefixo dis- e alma decodificará o complexo disalmadu, o que não exclui um certo conhecimento do português. Em suma, os exemplos desse nível entram no que poderíamos chamar de etimológico, ou seja, apesar de haver diversas ocorrências, elas provêm da língua lexificadora.

No nível 4, entram complexos cuja base ou não existe independentemente (*kisi, *maia, *dangu, *pi) ou, quando existe algo fonologicamente semelhante ( $f i u$ 'fio, feio'; manca 'mancha'; pidi 
'pedir, peido') seu signficado que nada tem a ver com o significado do todo. Enfim, o complexo formado por prefixo mais base é semanticamente opaco, não-produtivo, lexicalizado. Mesmo assim, creio que se pode afirmar que o prefixo dis- está presente em todas as palavras dos Quadros 1 e 2.

Vejamos o caso mais problemático, o nível 4. Há motivação tanto morfológica quanto semântica para a análise dos exemplos em dis + base. Do ponto de vista morfológico, a seqüência inicial de fonemas /dis-/ é identificada pelo falante como sendo da mesma classe que a que ocorre nas palavras do nível 1 (e nas do nível 2). Semanticamente, o significado do complexo é de DES-AÇÃO, o que se deve pelo menos em parte à presença de dis-. Portanto, a despeito da opacidade semântica da base, essas palavras devem ser decompostas. Seria um equívoco não reconhecer que em algum lugar do componente morfológico da gramática eles são decomponíveis, a despeito de LIEBER (1992). Com efeito, o objetivo de uma teoria lingüística não é apenas gerar a descrição mais econômica para os fatos de língua. Mais importante do que isso é dar conta da intuição dos falantes. Por que considerar as palavras de nível 4 como não tendo nada a ver morfologicamente com as de nível 1 diante da realidade semântica e da intuição dos usuários da língua?

De um modo geral, o significado das formações morfológicas de nível 1 e 2 resulta dos significados parciais dos formativos que as compõem, mesmo que apenas parcialmente, como nas de nível 2. O significado das formações de nível 4, ao contrário, só pode ser deduzido a partir do complexo como um todo. O formativo da base deve ser entendido como a própria origem grega da palavra "morfema" (morphé = forma) sugere, portanto destituído de significado próprio independente do significado do todo. O formativo prefixal, por seu turno, indica sempre DES-AÇÃO. Portanto, a interpretação semântica das palavras complexas deve ser feita em níveis diferentes.

Diante do que foi dito, no domínio do componente morfológico da gramática, ou seja, da gramática morfológica, a análise de dis.dangu 
é exatamente igual à de dis.kansa, como mostrado em (12). O que diferencia as duas, e as outras das repectivas classes, é o nível da morfologia em que cada uma deve ser analisada.

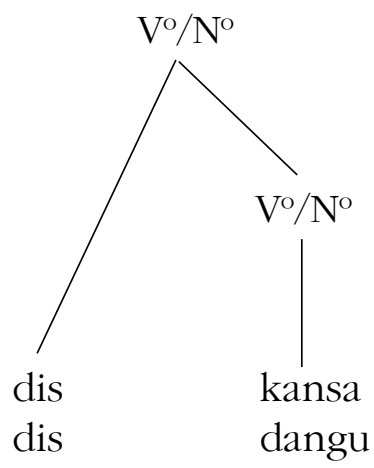

Abaixo do nível 4 aparentemente viria o que alguns autores chamam de morfologia prosódica (McCARHY \& PRINCE, 1993, 1995; COUTO, 2000). Seria um "nível 5". Seguindo essa teoria, eu propus que os falantes decomporiam determinadas palavras em partes que, a despeito de terem material fonológico próprio, não têm significado próprio. Assim, no hipocorístico guineense Lalau haveria uma base Lala-, que constaria da reduplicação da sílaba ótima CV, formando a palavra fonológica (prosódica) ótima, como no caso de Pipi 'Pedro', Nonó (?) e muitos outros. O - u seria algo a mais, um apêndice ou "sufixo". Algo semelhante acontece com palavras como Copacabana, que os falantes de alguma forma sentiriam como se se constituísse de Copa mais cabana (COUTO, 2000).

É no "nível 5", ou no imediatamente seguinte, que se aplicariam as regras de silabificação. A seqüência de sílabas de Copa-é a mesma de copa (de árvore, por exemplo), portanto, Copa- deve ser um formativo morfológico. O mesmo se dá com -cabana. Entretanto, nem sempre, a segmentação em formativos morfológicos coincide com a silabificação. Isso fica patente no caso de dis.aparsi (nível 1) e de dis.afiu (nível 4). A silabificação deve ser /di-sa-par-si/ e /disa-fiu/, respectivamente. 
As regras fonológicas aparentemente viriam após o "nível 5" (prosódico), uma vez que a silabificação se dá no nível subjacente. Elas entrariam no que se tem chamado de camada melódica ou segmental. Esta proposta está em perfeita sintonia com a da fonologia e morfologia lexical bem como com a das fonologias não-lineares.

Não se trataria de pura e simples aplicação da fonologia e morfologia lexical de Kiparsky. Tratar-se-ia antes de aproveitar a idéia de que as palavras da língua devem ser analisadas em níveis diferentes. Com efeito, no modelo desse autor, no nível mais alto entram as formas irregulares. No nível mais baixo, entram as formações regulares. Aqui se inverte essa direcionalidade, o que em princípio não seria nenhum problema.

\section{CONSIDERAÇÕES FINAIS}

Gostaria de terminar reiterando as indagações que os dados discutidos sugeriram. A primeira é a de qual a razão de a criança, no processo de aquisição de sua L1, morfologizar primeiro a DESAÇÃ̃o, a despeito de em sua manipulação dos objetos, e em sua relação com o adulto, aparentemente fazer uso tanto dela quanto da RE-AÇÃO.

A segunda questão é a de por que o caboverdiano tem manifestações tanto de des- quanto de re-, embora em menor grau, enquanto que no guineense só ocorre des-. Nos crioulos do golfo da Guiné, aparentemente, nem des-ocorre. Nos crioulos franceses, a tendência é a mesma: se ocorre só um deles, é des-; se ocorrem ambos, des-é mais freqüente.

A terceira questão é o por que de, por exemplo, des-ocorrer menos do que re-nas variedades padrão e mais do que re-nas variedades rurais do português brasileiro.

Voltemos à existência de dis-, ao lado da inexistência de *ri-, em guineense, a despeito do hapax legomenon de (3i). O que se pode afirmar com segurança é que os falantes dessa língua sentiram necessidade do primeiro mas, pelo menos aparentemente, não do segundo. A ilação mais ampla que se pode tirar disso é a de que 
qualquer recurso lingüístico só surge quando os membros da comunidade de falantes sentem necessidade dele. Assim, aparentemente os guineenses ainda não sentiram necessidade de substituir fasi mas ou torna fasi por *ri.fasi. A recíproca também é verdadeira: sempre que a comunidade de falantes sente necessidade de determinado recurso expressivo, ele aparece, não importando de onde ele seja tirado (os empréstimos o comprovam a todo instante). De qualquer forma, os dados discutidos acima parecem sugerir que a solução não está apenas na língua. Talvez ela deva ser procurada no ambiente em que ela é falada.

Enfim, não consegui dar uma resposta definitiva às questões formuladas acima. No entanto, a própria vitalidade delas, expressa no número de ocorrências, como defende a lingüística de corpus (BIBER, CONRAD \& REPPEN, 1998), parece representar o primeiro passo na direção de uma explicação.

\section{REFERÊNCIAS BIBLIOGRÁFICAS}

ANDREOLETTI, Luis. Ditus kriolus. Pessano: Stampa MIMEP, s/d.

BARROS, Pe. Marcelino Marques de. O guineense. Revista Lusitana, v. V, fasc. 4, p. 272-300, 1897-1899.

BASÍLIO, Margarida. Estruturas lexicais do Português: uma abordagem gerativa. Petrópolis: Vozes, 1979.

BIBER, Douglas; CONRAD, Susan; REPPEN, Randi. Corpus linguistics: investigating language structure and use. Cambridge: Cambridge University Press, 1998.

BROUSSEAU, Anne-Marie; FILIPOVICH, Sandra; LEFEBVRE, Claire. Morphological processes in Haitian creole: the question of substrate and simplification. Journal of pidgin and creole languages 4,1.1-36, 1989.

CHAUDENSON, Robert. Le lexique du parler créole de la Réunion, tome II. Paris: Librairie Honoré Champion, 1974.

CLARK, Eve V. The lexicon in acquisition. Cambridge: Cambridge University Press, 1993. 
COUTO, Hildo Honório do. O crioulo português da Guiné-Bissau. Hamburgo: Helmut Buske Verlag, 1994. 50-65, 2000.

Os hipocorísticos crioulos e o conceito de palavra ótima. Papia 10, p.

DeGRAFF, Michel. Morphology in creole genesis. A sair em KENSTOWICZ, Michael (Org.). Ken Hale: A life in language. Cambridge, MA: MIT Press, 2000.

HOLM, John. A theoretical model for semi-criolization. Comunicação lida na 9th Conference of the Society for Caribbean Linguistics, University of West Indies, Cave Hill, Barbados, 26-29/8/1991.

KIHM, Alain. Kriyol syntax. Amsterdam: John Benjamins, 1994.

KIPARSKY, Paul. Word-formation and the lexicon. In: INGEMANN, F. (Org.). Proceedings of the Mid-West Linguistics conference. Lawrence: University of Kansas. 1982. p. 3-29.

LIEBER, Rochelle. Deconstructing morphology. Chicago: The University of Chicago Press, 1992.

McCARTHY, John; PRINCE, Alan. Prosodic morphology I. New Brunswick, NJ: Rutgers University, 1993.

. Prosodic morphology. In: GOLDSMITH, John A. (Ed.) The handbook of phonological theory. Oxford: Blackwell, 1995. p. 318-366.

McWHORTER, John. Identifying the creole prototype: vindicating a typological class. Language 74, 4, p. 788-818, 1998.

MONTENEGRO, Teresa; MORAIS, Carlos. Junbai. Bolama: Imprensa Nacional/ INACEP, 1979.

1994-1996.

Contes créoles de Guinée-Bissau (Série). Bissau: Ku Si Mon Editora, . Uori: storias de lama e philosophia. Bissau: Ku Si Mon Editora, 1995.

PAULISSEN, Det; ZONNEVELD, Wim. Compound verbs and the adequacy of lexical morphology. In: EVERAERT, Martin et al. (Org.). Morphology and modularity. Dordrecht: Foris Publications, 1988. p. 281-302.

PEREIRA, Augusto. Lubu ku lebri ku mortu i utrus storya di Guiné-Bissau. Bissau: Editora Nimba, 1988. v. I.

. Lubu ku lebri ku mortu i utrus storya di Guiné-Bissau. Bissau: Editora Nimba, 1989. v. II. 
PINTO, Clarice Pereira. A prefixação: um estudo comparativo entre o português padrão, o português rural e os crioulos de base portuguesa. 1994. Dissertação (Mestrado) - Universidade de Brasília.

POTTIER, Bernard. Systématique des éléments de relation: étude de morphosyntaxe structurale romane. Paris: Librairie Klincksieck, 1962.

1968. . Lingüistica moderna y filología hispánica. Madri: Editorial Gredos,

ROUGÉ, Jean-Louis. Petit dictionnaire étymologique du kriol de guinée-Bissau et Casamance. Bissau: INEP, 1988.

SANDMANN, Antônio José. Formação de palavras no português brasileiro contemporâneo. Curitiba/São Paulo: Scientia et Labor/Icone, 1989.

SCANTAMBURLO, Luigi. Dicionário do guineense. Lisboa: Edições Colibri, 1999. V. I: Introdução e notas gramaticais.

SMITH (Org.) The structure of phonological representations. Dordrecht: Foris.

VEIGA, Manuel. Diskrison strutural di lingua kabuverdianu. Praia: Institutu Kabuverdianu di livru, 1982. 